\title{
Respiratory disorders during sleep in chronic obstructive pulmonary disease
}

\author{
Oreste Marrone \\ Adriana Salvaggio \\ Giuseppe Insalaco \\ Istituto di Biomedicina e Immunologia \\ Molecolare, Consiglio Nazionale delle \\ Ricerche, Palermo, Italy
}

\begin{abstract}
Patients with COPD may show slow, progressive deteriorations in arterial blood gases during the night, particularly during rapid eye movement (REM) sleep. This is mainly due to hypoventilation, while a deterioration of ventilation/perfusion mismatch plays a minor role. The severity of gas exchanges alterations is proportional to the degree of impairment of diurnal pulmonary function tests, particularly of partial pressure of oxygen $\left(\mathrm{PaO}_{2}\right)$ and of carbon dioxide $\left(\mathrm{PaCO}_{2}\right)$ in arterial blood, but correlations between diurnal and nocturnal blood gas levels are rather loose. Subjects with diurnal $\mathrm{PaO}_{2}$ of $60-70 \mathrm{mmHg}$ are distinguished in "desaturators" and "nondesaturators" according to nocturnal oxyhemoglobin saturation behavior. The role of nocturnal hypoxemia as a determinant of alterations in sleep structure observed in COPD is dubious. Effects of the "desaturator" condition on pulmonary hemodynamics, evolution of diurnal blood gases, and life expectancy are also controversial. Conversely, it is generally accepted that occurrence of sleep apneas in COPD is associated with a worse evolution of the disease. Nocturnal polysomnographic monitoring in COPD is usually performed when coexistence of sleep apnea ("overlap syndrome") is suspected, while in most other cases nocturnal oximetry may be enough. Nocturnal oxygen attenuates sleep desaturations among stable patients, without increases in $\mathrm{PaCO}_{2}$ of clinical concern. Nocturnal treatment with positive pressure ventilators may give benefit to some stable hypercapnic subjects and patients with the overlap syndrome.
\end{abstract}

Keywords: COPD, sleep, hypoxemia, oxygen, mechanical ventilation

Chronic obstructive pulmonary disease (COPD) is usually diagnosed in subjects with a clinical history of exposure to pulmonary risk factors who show a poorly reversible bronchial obstruction (NHLBI/WHO 2005). During wakefulness, abnormalities of respiratory function are demonstrated by standard pulmonary function tests (PFTs): among them, spirometry and arterial blood gas analysis are the most generally used to define the degree of severity of COPD. A more complete evaluation of patients with this disease includes the assessment of sleep gas exchanges, which worsen to a variable extent with respect to wakefulness.

COPD is a high and increasingly prevalent disease. At present, its treatment only partially affects prognosis and quality of life. Our ability to predict prognosis of affected patients is improving (Celli et al 2004), but is still imperfect. A better knowledge of the aspect of respiratory function during sleep could probably improve our approach to the disease.

\section{Features of sleep respiratory disorders in COPD}

During sleep, minute ventilation physiologically decreases with respect to wakefulness (Douglas, White, Pickett, et al 1982), while pressure of oxygen in arterial blood $\left(\mathrm{PaO}_{2}\right)$ falls and pressure of carbon dioxide $\left(\mathrm{PaCO}_{2}\right)$ increases (Midgren and Hansson 1987). In healthy young subjects, as well as in many patients with respiratory diseases who are normoxemic while awake, the $\mathrm{PaO}_{2}$ reduction does not significantly reduce 
oxyhemoglobin saturation $\left(\mathrm{SaO}_{2}\right)$. Instead, when $\mathrm{PaO}_{2}$ is close to, or in, the steep portion of the oxyhemoglobin dissociation curve, $\mathrm{SaO}_{2}$ falls are common.

Likewise, in COPD diurnal $\mathrm{PaO}_{2}$ is correlated with nocturnal desaturations. In non-REM sleep, large $\mathrm{SaO}_{2}$ falls are uncommon, unless blood gas tensions during wakefulness are severely impaired. The most common finding is a small $\mathrm{SaO}_{2}$ reduction, while the breathing pattern remains substantially regular. Instead, prolonged oxygen desaturations are often observed throughout rapid eye movement (REM) sleep (Douglas et al 1979; Catterall et al 1983) (Figure 1). Long duration (often several minutes) and a slow resolution distinguish such desaturations from the typical desaturations of sleep apneas that rarely exceed a minute and are rapidly reverted (Bonsignore et al 1990). Prolonged hypoxemic episodes in REM sleep are not specific of COPD, but can also occur in other respiratory diseases (Becker et al 1999) and, to some extent, in healthy elderly subjects (Aber et al 1989). Polygraphic signals recorded during such episodes do not always show well-defined alterations of ventilatory activity. They often suggest the occurrence of prolonged hypoventilation (Douglas et al 1979), or of hypopneas with either prevalent obstructive or central characteristics (White et al 1995). Irregularities of the breathing pattern, resembling those of normal subjects, often occur during phasic eye movement activity; they are characterized by short changes in depth and frequency of ventilation, and are often enough to cause some oxygen desaturation (George et al 1987).

Due to difficulties in monitoring, less information is available about $\mathrm{PaCO}_{2}$ changes. Invasive (Fletcher et al 1983;
Catterall et al 1985), as well as transcutaneous (Midgren and Hansson 1987; Aubry et al 1989; O’Donoghue et al 2003), measurements showed a variable increase in $\mathrm{PaCO}_{2}$ during sleep that was proportional to $\mathrm{PaCO}_{2}$ during wakefulness (Aubry et al 1989; O’Donoghue et al 2003).

In some patients, COPD coexists with obstructive sleep apnea (OSA). This association is often referred to as "overlap syndrome" (Flenley 1985). Whether prevalence of OSA among patients with COPD is higher than (Chaouat et al 1995; Larsson et al 2001), or similar as (Sanders et al 2003; Bednarek et al 2005), in the general population is controversial. Differences in criteria of subjects' recruitment may partly explain these contrasting results. In overlap patients, characteristics of sleep-disordered breathing (SDB) may resemble more those of OSA or of COPD, depending on which condition is preponderant.

\section{Predictors of blood gas alterations during sleep}

Among COPD patients, $\mathrm{SaO}_{2}$ values during sleep are significantly correlated with diurnal values (Fleetham et al 1982; Connaughton et al 1988; Vos et al 1995). For similar wake $\mathrm{PaO}_{2}$, desaturations tend to be worse in hypercapnic than in normocapnic subjects (Perez-Padilla et al 1987; Bradley et al 1990). This is in agreement with the early observations that desaturations during sleep are worse in "blue bloaters" than in "pink puffers" (Douglas et al 1979; Catterall et al 1983). As long as blood gases during

\section{$\mathrm{SaO}_{2}$}

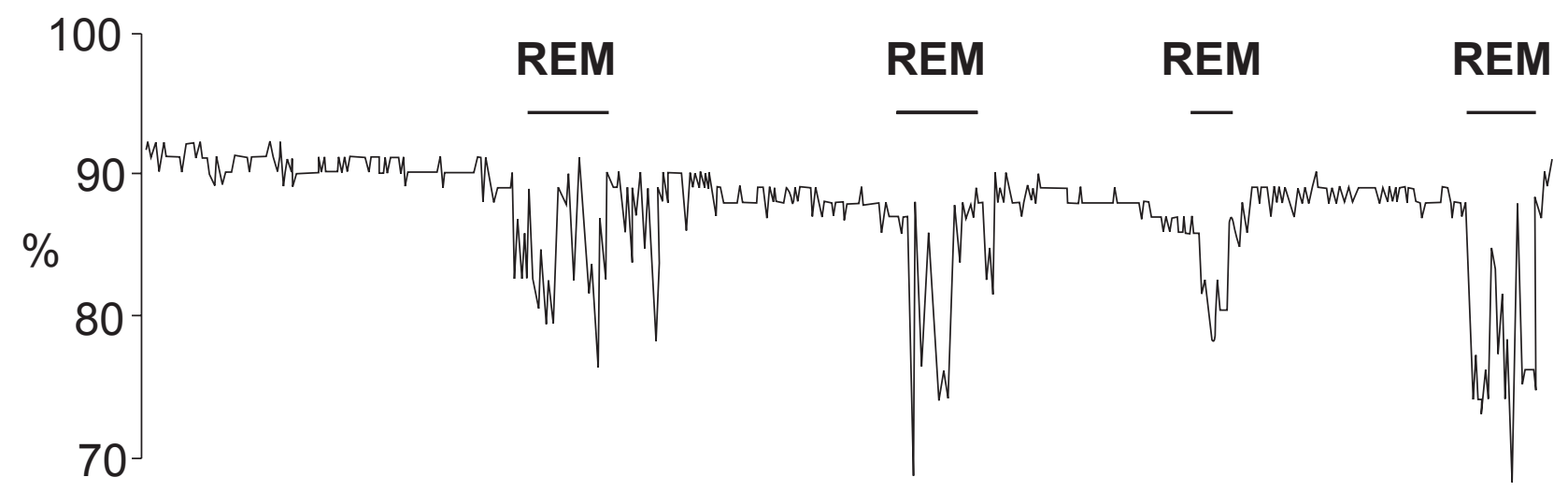

\section{1 hour}

Figure I Recording of nocturnal oxyhemoglobin saturation during one night in a patient with COPD. Observe the prolonged desaturations during REM sleep stages. Abbreviations: COPD, chronic obstructive pulmonary disease; $\mathrm{REM}$, rapid eye movement; $\mathrm{SaO}_{2}$, oxyhemoglobin saturation. 


\section{REM sleep}

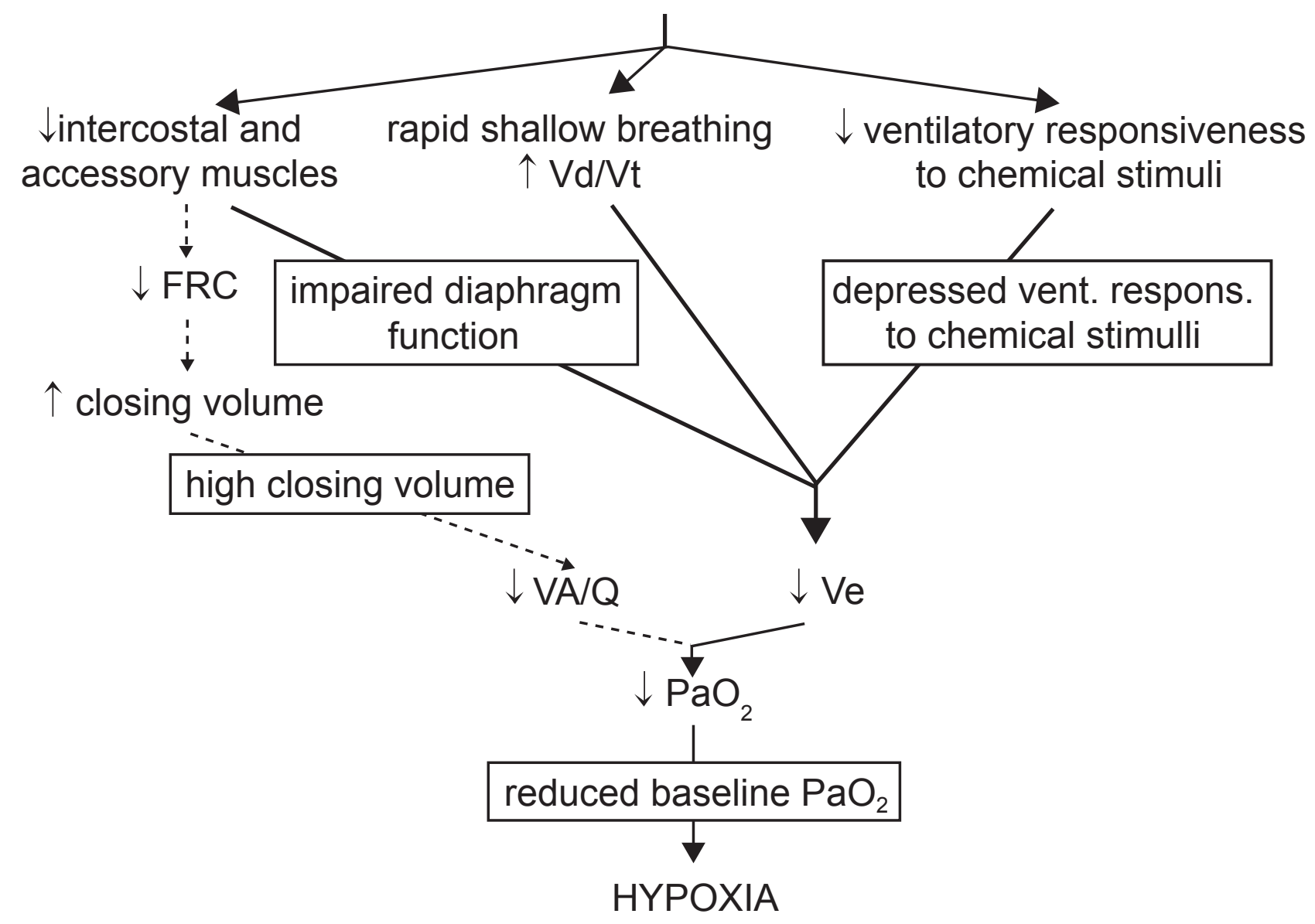

Figure 2 Mechanisms leading to appearance or worsening of hypoxemia during REM sleep in COPD.

Abbreviations: COPD, chronic obstructive pulmonary disease; $\mathrm{FRC}$, functional residual capacity; $\mathrm{REM}$, rapid eye movement; $\mathrm{PaO}$, pressure of oxygen in arterial blood.

wakefulness deteriorate in the natural course of the disease, nocturnal desaturations will deteriorate as well (Pépin et al 1989). Ventilatory responses to hypoxia (Tatsumi et al 1986) and hypercapnia (Fleetham et al 1980; Tatsumi et al 1986; Vos et al 1995) during wakefulness are inversely correlated with desaturations during sleep, but it is not clear to what extent such correlations are independent of diurnal blood gas tensions. The importance of mechanical impairment as independent predictor of nocturnal desaturations is controversial. One study found that inspiratory muscles strength was correlated to nocturnal $\mathrm{SaO}_{2}$, although its possible influence was small as compared with that of $\mathrm{PaO}_{2}$ and forced expiratory volume in one second $\left(\mathrm{FEV}_{1}\right)$ (Heijdra et al 1995). $\mathrm{FEV}_{1} /$ forced vital capacity (FVC) was found to be a significant predictor of sleep desaturations among patients with mild COPD (Sanders et al 2003). By contrast, other studies showed that any predictivity of $\mathrm{FEV}_{1}$ for sleep desaturations disappeared when blood gases were considered (Perez-Padilla et al 1987; Bradley et al 1990).
Precise determination of nocturnal $\mathrm{SaO}_{2}$ has a different importance in patients with a different severity of the disease. In patients with normal or almost normal blood gas tensions during wakefulness, occurrence of significant hypoxemia during sleep is unlikely, due to the correlation between diurnal $\mathrm{PaO}_{2}$ and nocturnal $\mathrm{SaO}_{2}$. In patients with severe hypoxemia during wakefulness, $\mathrm{SaO}_{2}$ shows a further reduction during sleep; its precise evaluation could induce to administer a higher oxygen flow in the nocturnal hours. In patients with mildly reduced $\mathrm{PaO}_{2}$ during wakefulness, hypoxemia of some relevance may or may not occur during sleep. Therefore particular attention has been paid to subjects with diurnal $\mathrm{PaO}_{2}$ ranging between $60 \mathrm{mmHg}$ and $70 \mathrm{mmHg}$. Two criteria have been proposed to define such patients as "desaturators": a) a $\mathrm{SaO}_{2}$ fall below 90\% lasting $\geq 5$ minutes, with a nadir level $\leq 85 \%$ (Fletcher et al 1987); b) $\mathrm{SaO}_{2}$ values $<90 \%$ for $\geq 30 \%$ of a whole nocturnal recording (Levi-Valensi et al 1990). Diurnal $\mathrm{PaO}_{2}$ and $\mathrm{PaCO}_{2}$ are worse in desaturators than 
in nondesaturators, but only nocturnal instrumental monitoring allows us to reliably distinguish the two groups (Fletcher et al 1987).

\section{Pathogenesis of hypoxemia during sleep}

Physiological modifications of respiratory control and muscular activity occurring during sleep do not result in hypoxemia in most normal subjects. In COPD patients, similar modifications interfere with the respiratory function alterations typical of the disease, and may lead to appearance or worsening of hypoxemia and hypercapnia.

Some deterioration of gas tensions may be already observed before sleep when assuming a recumbent posture, which causes a reduction in functional residual capacity (FRC) and, possibly, an increase in closing volume.

Cough reflex is lost with sleep onset (Sullivan et al 1979), which facilitates mucus accumulation in the airway, and enhances ventilation/perfusion mismatch throughout the whole sleep time.

In non-REM sleep the decrease in minute ventilation is not usually responsible for marked modifications in gas tensions, while more significant blood gas derangements occur during REM sleep (Figure 2).

In REM sleep, several factors can contribute to reduce alveolar ventilation. In this sleep state, respiratory activity relies almost exclusively on the diaphragm, while the activity of intercostal (Tabachnik et al 1981) and accessory muscles (Johnson and Remmers 1984) ceases. As in COPD the efficiency of diaphragmatic contraction is impaired, minute ventilation markedly decreases (Hudgel et al 1983; Ballard et al 1995). A decrease in minute ventilation may be favored by an increase in upper airway resistance and by a reduction in neuromuscular output (Ballard et al 1995). Ventilatory responsiveness to chemical stimuli physiologically decreases in REM sleep (Anthonisen and Kryger 1982; Douglas, White, Weil, et al 1982), which may be of particular concern in subjects whose responsiveness is already low during wakefulness. Eventually, bursts of rapid shallow breathing frequently occur, mainly in coincidence with eye movements (George et al 1987), and may cause an increase in ventilation of the dead space with a decrease in alveolar ventilation.

Invasive cardiorespiratory measurements during sleep suggested an important contribution of increased ventilation/ perfusion mismatch during REM sleep to nocturnal hypoxemia in COPD (Fletcher et al 1983); however, the real significance of such measurements was later questioned, as they were performed in non steadystate conditions (Catterall et al 1985). Theoretically, an increased ventilation/perfusion mismatch could follow loss of accessory inspiratory muscles activity (Johnson and Remmers 1984), causing a decrease in FRC and an increase in closing volume. Noninvasive measurements performed by inductive plethysmography suggested that FRC

Table I Consequences of nocturnal hypoxemia and hypercapnia in COPD

\begin{tabular}{|c|c|c|}
\hline & Acute & Chronic \\
\hline $\begin{array}{l}\text { Sleep } \\
\text { structure }\end{array}$ & $\begin{array}{l}\text { Altered sleep structure in severe } \\
\text { COPD, but inconsistent improvement } \\
\text { of sleep with } \mathrm{O}_{2} \text { administration }\end{array}$ & $\begin{array}{l}\text { Worse sleep among pink puffers (mild } \\
\text { desaturators) than blue bloaters (severe } \\
\text { desaturators) }\end{array}$ \\
\hline Arrhythmias & $\begin{array}{l}\text { Arrhythmias observed during severe } \\
\text { sleep desaturations and prevented by } \mathrm{O}_{2} \text { administration }\end{array}$ & $\begin{array}{l}\text { Danger of arrhythmias not directly } \\
\text { documented }\end{array}$ \\
\hline $\begin{array}{l}\text { Pulmonary } \\
\text { artery pressure }\end{array}$ & $\begin{array}{l}\text { Increase in pulmonary artery } \\
\text { pressure during sleep desaturations }\end{array}$ & $\begin{array}{l}\text { Inconsistent findings about wake pulmonary } \\
\text { artery pressure differences between } \\
\text { "desaturators" and "nondesaturators" }\end{array}$ \\
\hline Diurnal blood gases & & $\begin{array}{l}\text { Similar wake blood gas evolution among } \\
\text { "desaturators" and "nondesaturators"; } \\
\text { possible worsening of blood gases in severe } \\
\text { patients suggested by beneficial effects of } \\
\text { ventilatory treatment }\end{array}$ \\
\hline Mortality & $\begin{array}{l}\text { Death preferentially occurring at } \\
\text { night among patients with exacerbations }\end{array}$ & $\begin{array}{l}\text { Prognosis independent of nocturnal } \\
\text { hypoxemia measured in stable conditions }\end{array}$ \\
\hline
\end{tabular}

Abbreviations: COPD, chronic obstructive pulmonary disease. 
could decrease during at least part of REM sleep (Hudgel et al 1983). Later, measurements performed in hyperinflated COPD subjects by means of body plethysmography in association with esophageal pressure ruled out this possibility (Ballard et al 1995); this suggests that, in COPD, hyperinflation persists during REM sleep due to loss of elastic lung recoil, despite loss of accessory muscle activity.

In summary, hypoventilation, secondary to the sleep state, is the most important determinant of REM-related hypoxemia in COPD patients. Some contribution of an increased ventilation/perfusion mismatch cannot be ruled out, but has not been clearly demonstrated. Nocturnal hypoxemia worsens along with the functional respiratory impairment, and particularly with deterioration of arterial blood gas tensions. The shape of the hemoglobin dissociation curve from oxygen accounts for the more marked drops in $\mathrm{SaO}_{2}$ among the subjects with diurnal hypoxemia.

\section{Consequences of sleep respiratory disorders}

Potential dangers of nocturnal hypoventilation episodes and of the associated hypoxemia in COPD are still uncertain (Table 1).

In patients with severe COPD, sleep structure is usually characterized by prevalence of light non-REM sleep stages and frequent arousals (Brezinova et al 1982). Such alterations were not present in patients with mild COPD with no coexistent apneas (Sanders et al 2003). Arousals were correlated to oxygenation during sleep in one study (Cormick et al 1986), and hypoxemic episodes were suspected to be responsible for sleep alterations. However, despite lower nocturnal $\mathrm{SaO}_{2}$ in "blue bloaters" than in "pink puffers", sleep quality evaluated by electroencephalogram (EEG) was not better in the latter group (Calverley et al 1982); besides, oxygen administration increased sleep duration in some experiences (Goldstein et al 1984; Aubry et al 1989), but proved ineffective at improving sleep structure or duration in other studies (Fleetham et al 1982; McKeon et al 1989; Lin 1996). A comparison between effects of oxygen alone, which improved nocturnal $\mathrm{SaO}_{2}$, and oxygen plus ventilatory treatment, which improved both $\mathrm{SaO}_{2}$ and transcutaneous $\mathrm{PaCO}_{2}$, showed that the latter led to a significantly greater improvement in sleep duration (Meecham Jones et al 1995): that supports a previous hypothesis that $\mathrm{PaCO}_{2}$ affects sleep quality more than oxygen tension (Fleetham et al 1982). Treatment by lung volume reduction surgery improved at the same time nocturnal oxygenation and sleep structure, but changes in sleep quality were not correlated to those in nocturnal oxygenation (Krachman et al 2005). Subjective reports confirmed that sleep quality is worse in COPD than in normal subjects. According to one study symptoms like cough or wheezing, and not degree of airway obstruction, are correlated to subjective sleep disturbances (Klink et al 1994), while another study pointed out the importance of comorbidities like depression or arthritis (Bellia et al 2003).

Hypoxemia during sleep enhances cardiac arrhythmias, at least when it is severe (Shepard et al 1985). Oxygen administration reduces nocturnal arrhythmias (Tirlapur and Mir 1982). It is unknown if such arrhythmias may influence life expectancy.

Hemodynamic monitoring during sleep in COPD showed that pulmonary arterial pressure (PAP) increases during hypoxemic episodes (Coccagna et al 1978; Boysen et al 1979; Fletcher et al 1984), and that oxygen administration prevents at the same time desaturations and PAP augmentations (Boysen et al 1979; Fletcher et al 1984). Whether or not desaturations occurring only during sleep in COPD are followed by a stable deterioration of pulmonary hemodynamics is still debated. Fletcher and colleagues (1989), who adopted the first definition for "desaturator", reported above, observed higher PAP values among desaturators than nondesaturators, and a better evolution of diurnal PAP among desaturators receiving, than among those not receiving, nocturnal oxygen (Fletcher et al 1992). When the second definition was used, cross-sectional studies showed either higher (Levi Valensi et al 1992) or similar (Chaouat et al 1997) PAP values among desaturators, while later longitudinal investigations demonstrated no influence of the “desaturator" condition (Chaouat et al 2001) and of oxygen administration (Chaouat et al 1999) on PAP. Rasche and colleagues (2001) reported that PAP during wakefulness was significantly correlated with lowest nocturnal $\mathrm{SaO}_{2}$, but not with time spent below $90 \% \mathrm{SaO}_{2}$.

It has been hypothesized that nocturnal hypoventilation may influence wake arterial blood gases. In subjects with mild diurnal hypoxemia, Chaouat and colleagues (2001) did not observe any trend toward a worse evolution of wake arterial blood gas tensions among desaturators than nondesaturators. By contrast, in subjects with chronic hypercapnic respiratory failure, prevention of nocturnal hypoventilation by ventilatory treatment was followed by an improvement in diurnal blood gases (Elliott et al 1992; Meecham Jones et al 1995; Sivasothy et al 1998). The relatively mild nocturnal hypoxemia in the patients of the first study, as opposed to the 
marked desaturations recorded in the others, could account for these apparently contrasting results.

The most important consequence of nocturnal hypoventilation could be a reduced life expectancy. Early observations on COPD patients hospitalized for exacerbation pointed out that death during hospital stay occurred preferentially in the nocturnal hours, suggesting that hypoxemia during sleep could immediately influence survival (McNicholas and Fitzgerald 1984). A later multicentre study on patients on long-term oxygen therapy, evaluated retrospectively, pointed out that nocturnal death does not often occur during sleep (Zielinski et al 1997). Besides, in other studies nocturnal hypoxemia did not show any independent role on the evolution of the disease (Connaughton et al 1988; Chaouat et al 2001).

Consequences of nocturnal SDB are much worse and clearer in the overlap syndrome. COPD and OSA, when associated, are of particular concern: they have a synergistic effect, often leading to impairment of diurnal arterial blood gases and to stable pulmonary hypertension that would not be warranted by the degree of severity of each of the diseases taken alone (Bradley et al 1986; Chaouat et al 1995).

\section{Monitoring of nocturnal respiratory function}

Nocturnal monitoring in COPD is performed to look for appearance of SDB, or to quantify worsening of blood gas exchanges during sleep and optimize treatment.

Polysomnography is a complex procedure consisting of simultaneous recording of sleep and cardio-respiratory parameters, and is usually performed throughout the night. It can detect disorders of ventilation and hypoxemic episodes, and allows us to temporally correlate them with sleep stages. Due to its high cost, its use must be limited. Theoretically, polysomnography is the most accurate method to explore nocturnal respiratory function, as it allows us to recognize possible underestimations of the usual degree of hypoxemia due to occasional lack of REM sleep during nocturnal monitoring. However, it has been shown that oxygen desaturations, as explored during polysomnography, are less than resulting from simple oximetry monitoring, due to poor tolerability of the polysomnographic equipment, and to a shorter sleep during polysomnographic than oximetry monitoring (Brijker et al 2001). Today, in patients with COPD polysomnography is mainly performed when the coexistence of OSA is suspected, due to symptoms like heavy snoring and excessive daytime sleepiness, or to fatigue, pulmonary hypertension or polycythemia out of proportion to the diurnal PFTs alterations (Kushida et al 2005).

Oximetry is inexpensive, and easy to perform and to tolerate. Modern instruments can be applied for prolonged ambulatory monitoring, keeping in memory consecutive diurnal and nocturnal data. Severity of hypoxemia and need of oxygen treatment may appear quite different when $\mathrm{SaO}_{2}$ values recorded during diurnal rest and activity, as well as during the night, are taken into account at the same time, than when just instantaneous $\mathrm{PaO}_{2}$ at rest and $\mathrm{SaO}_{2}$ during exercise are considered (Sliwinski et al 1994; Pilling and Cutaia 1999; Fussell et al 2003). As regards $\mathrm{SaO}_{2}$ monitoring during sleep, today simple oximetry tends to be preferred over polysomnography in most COPD patients. Mean and lowest nocturnal levels, and time spent below $90 \%$ or $85 \%$ values are $\mathrm{SaO}_{2}$ measurements most commonly performed. Mean $\mathrm{SaO}_{2}$ is quite reproducible. Time spent below $90 \%$ is probably the most generally considered $\mathrm{SaO}_{2}$ parameter, as it is used to distinguish patients with mild diurnal hypoxia into desaturators and nondesaturators (Levi-Valensi et al 1990); however, it is highly variable between nights, suggesting that it may be appropriate to record oximetry for multiple, rather than for a single night (Lewis 2003).

\section{Treatment of sleep respiratory disorders}

In COPD exacerbations, a worsening in gas exchanges during sleep must be expected; mechanical ventilation is required (Lightowler et al 2003), but there are no guidelines taking into account nocturnal blood gas exchanges for such treatment in this condition.

So far, most studies on respiration during sleep in COPD have regarded patients in a clinically stable state. In such patients, treatment of nocturnal hypoxia may consist of drugs, oxygen, or mechanical ventilation.

Little importance is usually attributed to drug treatment for hypoxemia during sleep in COPD. Among substances with bronchodilating effects, theophylline caused an improvement in hypoxemia, but sometimes at the expense of a worsening in sleep quality (Mulloy and McNicholas 1993); more recently, thiotropium bromide has been shown to determine some increase in nocturnal $\mathrm{SaO}_{2}$ without interfering with sleep quality (McNicholas et al 2004).

Oxygen and noninvasive ventilatory treatment correct more effectively nocturnal desaturations.

In stable hypoxic patients, oxygen is usually administered during part of the day and throughout the nocturnal hours 
(NOTT 1980; MRC 1981; NHLBI/WHO 2005). In clinically stable hypercapnic COPD patients without sleep apnea for whom long-term oxygen therapy (LTOT) was indicated, nocturnal oxygen administration at a flow rate sufficient to ensure a diurnal $\mathrm{SaO}_{2} \geq 90 \%$ prevented oxyhemoglobin desaturations, and caused a larger increase in transcutaneous $\mathrm{PaCO}_{2}$ than breathing room air (Goldstein et al 1984; Aubry et al 1989), not of clinical concern (Goldstein et al 1984). However, sleep desaturations are not always adequately corrected by oxygen administered at that flow rate, especially in the most hypercapnic subjects (Plywaczewski et al 2000). What increase in oxygen flow is necessary in the nocturnal hours in patients on LTOT to prevent oxygen desaturation is not clear. It has been empirically proposed to increase oxygen flow at night by 1 liter/minute (ATS 1995), although an observation on a small number of patients suggested that a 0.5 liter/minute increase could be sufficient (Servera et al 1994). Nocturnal monitoring can be of help for the prescription of the most appropriate nocturnal oxygen flow.

In patients for whom LTOT is not indicated on the basis of the diurnal $\mathrm{PaO}_{2}$ level, advantages of nocturnal oxygen administration are still uncertain. The contrasting results about the effects on pulmonary hemodynamics of oxygen administered during the night for two or three years in desaturators have been mentioned above (Fletcher et al 1992; Chaouat et al 1999). One study on a small number of subjects suggested that desaturators' survival could benefit from long-term nocturnal oxygen, although results were not statistically significant (Fletcher et al 1992). However, a later study on a similar group of subjects could not find any effect of nocturnal oxygen on either survival or deterioration in diurnal blood gases and delay in requirement of LTOT (Chaouat et al 1999).

Noninvasive nocturnal ventilatory treatment in stable COPD patients may be taken into account for some subjects with a severe form of the disease. Despite in these subjects hypoxemia is present during the whole day, in several cases mechanical ventilation may be applied only during the night, so as to correct the worst desaturations of the 24 hours, and not to interfere with daily activities. Treatment is performed by positive pressure ventilators, more often by means of pressure support or by bilevel devices. If appropriately set, during their application $\mathrm{SaO}_{2}$ and $\mathrm{PaCO}_{2}$ levels can improve at the same time (Elliott et al 1992; Meecham-Jones et al 1995). In some subjects, nocturnal application of mechanical ventilation may be of benefit also to diurnal blood gases after a few months (Elliott et al 1992; Meecham Jones et al 1995; Perrin et al 1997; Jones et al 1998;
Sivasothy et al 1998; Clini et al 2002). Mechanisms of such improvement are not entirely clear. It is unlikely that inspiratory muscle rest has some responsibility. Some improvement in chemosensitivity to $\mathrm{CO}_{2}$ and in pulmonary mechanics, possibly due to reduced interstitial edema, could play a role (Elliott et al 1991). On the average, compliance to, and benefits of, ventilatory treatment in COPD are less than in restrictive disorders (Leger et al 1994; Simonds and Elliott 1995). COPD patients to treat by mechanical ventilation must be carefully selected, must undergo a monitoring that demonstrates the efficacy of the ventilator setting in correcting nocturnal hypoventilation, and have to be adequately instructed and adapted to the ventilator use. Failure to fulfil some of these conditions may at least partly account for reports of unsuccessful trials with ventilatory treatment (Strumpf et al 1991; Gay et al 1996; Lin 1996; Casanova et al 2000). It has been proposed to prescribe long-term ventilatory treatment in association with oxygen administration to stable COPD subjects with symptoms suggestive of nocturnal hypoventilation (morning headache, apparently unwarranted fatigue or dyspnea) in one of the following conditions: a) a $\mathrm{PaCO}_{2} \geq 55 \mathrm{mmHg}$; b) a $\mathrm{PaCO}_{2} \geq 50 \mathrm{mmHg}$ associated with recurrent hypercapnic respiratory failure; or c) a $\mathrm{PaCO}_{2} \geq 50 \mathrm{mmHg}$ associated with nocturnal $\mathrm{SaO}_{2}$ values $\leq 88 \%$ for at least 5 consecutive minutes despite oxygen administration at 2 liters/minute (CC 1999). In addition to effects on gas exchanges, ventilatory treatment may be associated with an improvement in quality of life (Meecham-Jones et al 1995; Perrin 1997; Sivasothy et al 1998; Clini et al 2002) and with a more prolonged nocturnal sleep, observed at polysomnography after a few months of treatment (Elliott et al 1992; Meecham-Jones et al 1995). An effect on survival and on number of exacerbations with an up to three-year treatment has not been demonstrated (Sivasothy et al 1998; Casanova et al 2000).

Indications and outcomes of mechanical ventilation are different in patients with the overlap syndrome. Due to the deleterious effects of the association of OSA to COPD, previously mentioned (Bradley et al 1986; Chaouat et al 1995), treatment by nocturnal ventilation must be performed in most of these patients. Continuous positive airway pressure (CPAP) is effective to eliminate obstructive apneas, but is not always enough to correct hypoxemia during sleep. Nocturnal monitoring can help us to decide if CPAP must be replaced by other kinds of ventilations (usually bilevel positive pressure ventilation), and if it is necessary to associate oxygen administration with ventilatory treatment. 


\section{Conclusions}

Important questions remain unanswered several decades after studies on respiratory function in COPD began. In particular, the real danger represented by nocturnal oxygen desaturations independently of diurnal blood gas levels, and the need to specifically address their treatment are still unclear. Most uncertainty comes from the correlation between diurnal and nocturnal blood gas levels that makes it difficult to identify the separate effects of wake and sleep hypoxemia. To separately investigate the effects of sleep hypoxemia, many studies were done on patients with hypoxemia occurring only in the nocturnal hours: however, such patients often show sleep $\mathrm{SaO}_{2}$ values only slightly below $90 \%$, and for only part of the night. Negative results coming from such studies, rather than demonstrating lack of importance of nocturnal hypoxemia, could just indicate that moderate hypoxemia persisting only for a small portion of the 24 hours is of little concern. Severe nocturnal hypoxemia in patients with more advanced disease could be more dangerous, but its independent role is difficult to demonstrate, as it is almost always associated with a degree of hypoxemia during wakefulness whose deleterious effects are already well known. As reported above, some studies on the effects of nocturnal ventilatory treatment in hypercapnic patients suggested that correction of nocturnal blood gases derangements is of benefit, but positive results need to be confirmed. So far, all trials on treatment of nocturnal hypoxemia, either by oxygen or by mechanical ventilation, have been based on small numbers of individuals. Current indications on treatment of nocturnal hypoxemia (ATS 1995; CC 1999) are based on a limited knowledge, and it is not surprising that the attitude of physicians towards oxygen prescription for nocturnal hypoxemia remains variable (Wijkstra et al 2001). Long-term studies on large cohorts could help to give an answer to the still poorly known implications of $\mathrm{SDB}$ in COPD.

\section{References}

Aber WR, Block AJ, Hellard DW, et al. 1989. Consistency of respiratory measurements from night to night during the sleep of elderly men. Chest, 96:747-51.

Anthonisen NR, Kryger MH. 1982. Ventilatory and arousal responses to hypoxemia in sleep. Am Rev Respir Dis, 126:1-2.

[ATS] American Thoracic Society. 1995. Standards for the diagnosis and care of patients with chronic obstructive pulmonary disease. Am Rev Respir Dis, 152:S77-120.

Aubry P, Rose D, Arlatis S, et al. 1989. Bronchopneumopaties chroniques obstructives. Variations de la capnie au cours du sommeil en air ambiant et sous oxygène. Presse Med, 18:661-5.

Ballard RD, Clover CW, Suh BY. 1995. Influence of sleep on respiratory function in emphysema. Am J Respir Crit Care Med, 151:945-51.
Becker HF, Piper AJ, Flynn WE, et al. 1999. Breathing during sleep in patients with nocturnal desaturation. Am J Respir Crit Care Med, 159:112-8.

Bednarek M, Plywaczewski R, Jonczak J, et al. 2005. There is no relationship between chronic obstructive pulmonary disease and obstructive sleep apnea syndrome: a population study. Respiration, 72:142-9.

Bellia V, Catalano F, Scichilone N, et al. 2003. Sleep disorders in the elderly with and without chronic airflow obstruction: the SARA study. Sleep, 26:318-23.

Bonsignore G, Marrone O, Macaluso C, et al. 1990. Validation of oximetry as a screening test for obstructive sleep apnoea syndrome. Eur Respir $J, 11: 542 \mathrm{~s}-4 \mathrm{~s}$

Boysen PG, Block AJ, Wynne JW, et al. 1979. Nocturnal pulmonary hypertension in patients with chronic obstructive pulmonary disease. Chest, 76:536-42.

Bradley TD, Mateika J, Li D, et al. 1990. Daytime hypercapnia in the development of nocturnal hypoxemia in COPD. Chest, 97:308-12.

Bradley TD. Rutherford R, Lue F, et al. 1986. Role of diffuse airway obstruction in the hypercapnia of obstructive sleep apnea. Am Rev Respir Dis, 134:920-4.

Brezinova V, Catterall JR, Douglas NJ, et al. 1982. Night sleep of patients with chronic ventilatory failure and age matched controls: number and duration of the EEG episodes of intervening wakefulness and drowsiness. Sleep, 5:123-30.

Brijker F, van den Elshout FJ, Heijdra YF, et al. 2001. Underestimation of nocturnal hypoxemia due to monitoring conditions in patients with COPD. Chest, 119:1820-6.

Brochard L, Mancebo J, Wysocki M, et al. 1995. Noninvasive ventilation for acute exacerbations of chronic obstructive pulmonary disease. N Engl J Med, 333:817-22.

Calverley PM, Brezinova V, Douglas NJ, et al. 1982. The effect of oxygenation on sleep quality in chronic bronchitis and emphysema. Am Rev Respir Dis, 126:206-10.

Casanova C, Celli BR, Tost L. 2000. Long-term controlled trial of nocturnal nasal positive pressure ventilation in patients with severe COPD. Chest, 118:1582-90.

Catterall J, Calverley PM, McNee W, et al. 1985. Mechanism of transient nocturnal hypoxemia in hypoxic chronic bronchitis and emphysema. J Appl Physiol, 59:1698-703.

Catterall JR, Douglas NJ, Calverley PM, et al. 1983. Transient hypoxemia during sleep in chronic obstructive pulmonary disease is not a sleep apnea syndrome. Am Rev Respir Dis, 128:24-9.

[CC] Consensus Conference Report. 1999. Clinical indications for noninvasive positive pressure ventilation in chronic respiratory failure due to restrictive lung disease, COPD, and nocturnal hypoventilation. Chest, 116:521-34.

Celli BR, Cote CG, Marin JM, et al. 2004. The body-mass index, airflow obstruction, dyspnea, and exercise capacity index in chronic obstructive pulmonary disease. $N$ Engl J Med, 350:1005-12.

Chaouat A, Weitzenblum E, Kessler R, et al. 1997. Sleep-related $\mathrm{O}_{2}$ desaturation and daytime pulmonary haemodynamics in COPD patients with mild hypoxaemia. Eur Respir J, 10:1730-5.

Chaouat A, Weitzenblum E, Kessler R, et al. 1999. A randomized trial of nocturnal oxygen therapy in chronic obstructive pulmonary disease patients. Eur Respir J, 14:1002-8.

Chaouat A, Weitzenblum E, Kessler R, et al. 2001. Outcome of COPD patients with mild daytime hypoxaemia with or without sleep-related oxygen desaturation. Eur Respir J, 17:848-55.

Chaouat A, Weitzenblum E, Krieger J, et al. 1995. Association of chronic obstructive pulmonary disease and sleep apnea syndrome. Am J Respir Crit Care Med, 151:82-6.

Clini E, Sturani C, Rossi A, et al. 2002. The Italian multicentre study on noninvasive ventilation in chronic obstructive pulmonary disease patients. Eur Respir J, 20:529-38.

Coccagna G, Lugaresi E. 1978. Arterial blood gases and pulmonary and systemic arterial pressure during sleep in chronic obstructive pulmonary disease. Sleep, 1:117-24. 
Connaughton JJ, Catterall JR, Elton RA, et al. 1988. Do sleep studies contribute to the management of patients with severe chronic obstructive pulmonary disease? Am Rev Respir Dis, 138:341-4.

Cormick W, Olson LJ, Hensley MJ, et al. 1986. Nocturnal hypoxaemia and quality of sleep in patients with chronic obstructive lung disease. Thorax, 41:846-54.

Douglas N, Calverley PM, Legget RJ, et al. 1979. Transient hypoxaemia during sleep in chronic bronchitis and emphysema. Lancet, i:1-4.

Douglas NJ, White DP, Pickett CK. 1982. Respiration during sleep in normal man. Thorax, 37:840-4.

Douglas NJ, White DP, Weil JV, et al. 1982. Hypercapnic ventilatory response in sleeping adults. Am Rev Respir Dis, 126:758-62.

Dunroy HM, Adams L, Corfield DR, et al. 2003. $\mathrm{CO}_{2}$ retention in lung disease; could there be a pre-existing difference in respiratory physiology. Respir Physiol Neurobiol, 136:179-86.

Elliott MW, Mulvey DA, Moxham J, et al. 1991. Domiciliary nocturnal nasal intermittent positive pressure ventilation in COPD: mechanisms underlying changes in arterial blood gas tensions. Eur Respir $J, 4: 1044-52$.

Elliott MW, Simonds AK, Carroll MP, et al. 1992. Domiciliary nocturnal nasal intermittent positive pressure ventilation in hypercapnic respiratory failure due to chronic obstructive lung disease: effects on sleep and quality of life. Thorax, 47:342-8.

Fleetham J, West P, Mezon B, et al. 1982. Sleep, arousals, and oxygen desaturation in chronic obstructive pulmonary disease. The effect of oxygen therapy. Am Rev Respir Dis, 126:429-33.

Fleetham JA, Mezon B, West P, et al. 1980. Chemical control of ventilation and sleep arterial oxygen desaturation in patients with COPD. Am Rev Respir Dis, 122:583-9.

Flenley DC. 1985. Sleep in chronic obstructive lung disease. Clin Chest Med, 6:651-61.

Fletcher EC, Gray BA, Levin DC. 1983. Nonapneic mechanisms of arterial oxygen desaturation during rapid-eye-movement sleep. J Appl Physiol, 54:632-9.

Fletcher EC, Levin DC. 1984. Cardiopulmonary hemodynamics during sleep in subjects with chronic obstructive pulmonary disease. The effect of short- and long-term oxygen. Chest, 85:6-14.

Fletcher EC, Luckett RA, Goodnight-White S, et al. 1992. A double-blind trial of nocturnal supplemental oxygen for sleep desaturation in patients with chronic obstructive pulmonary disease and a daytime $\mathrm{PaO}_{2}$ above 60 mmHg. Am Rev Respir Dis, 145:1070-6.

Fletcher EC, Luckett RA, Miller T, et al. 1989. Pulmonary vascular hemodynamics in chronic lung disease patients with and without oxyhemoglobin desaturation during sleep. Chest, 95:757-64.

Fletcher EC, Miller J, Divine GW, et al. 1987. Nocturnal oxyhemoglobin desaturation in COPD patients with arterial oxygen tensions above $60 \mathrm{~mm} \mathrm{Hg}$. Chest, 92:604-8.

Fussell KM, Ayo DS, Branca P, et al. 2003. Assessing need for long-term oxygen therapy: a comparison of conventional evaluation and measures of ambulatory oximetry monitoring. Respir Care, 48:115-9.

Gay PC, Hubmayr RD, Stroetz RW. 1996. Efficacy of nocturnal nasal ventilation in stable, severe chronic obstructive pulmonary disease during a 3-month controlled trial. Mayo Clin Proc, 71:533-42.

George CF, West P, Kryger MH. 1987. Oxygenation and breathing pattern during phasic and tonic REM in patients with chronic obstructive pulmonary disease. Sleep, 10:234-43.

Goldstein RS, Ramcharan V, Bowes G, et al. 1984. Effect of supplemental nocturnal oxygen on gas exchange in patients with severe obstructive lung disease. $N$ Engl J Med, 310:425-9.

Heijdra YF, Dekhuijzen PN, Vos PJ et al. 1995. Nocturnal saturation and respiratory muscle function in patients with chronic obstructive pulmonary disease. Thorax, 50:610-12.

Hudgel D, Martin RJ, Capehart M, et al. 1983. Contribution of hypoventilation to sleep oxygen desaturation in chronic obstructive pulmonary disease. J Appl Physiol, 55:669-77.
Hudgel DW, Martin RJ, Capehart M, et al. 1983. Contribution of hypoventilation to sleep oxygen desaturation in chronic obstructive pulmonary disease. J Appl Physiol, 55:669-77.

Johnson MW, Remmers JE. 1984. Accessory muscle activity during sleep in chronic obstructive pulmonary disease. J Appl Physiol, 57:1011-17.

Jones SE, Packham S, Hebden M, et al. 1998. Domiciliary nocturnal intermittent positive pressure ventilation in patients with respiratory failure due to severe COPD: long-term follow up and effect on survival. Thorax, 53:495-8

Klink ME, Dodge R, Quan SF. 1994. The relation of sleep complaints to respiratory symptoms in a general population. Chest, 105:151-4.

Krachman SL, Chatila W, Martin UJ, et al. 2005. Effects of lung volume reduction surgery on sleep quality and nocturnal gas exchange in patients with severe emphysema. Chest, 128:3221-8.

Kushida CA, Littner MR, Morgenhaler T, et al. 2005. Practice parameters for the indications for polysomnography and related procedures: An Update for 2005. Sleep, 28:499-521.

Larsson LG, Lindberg A, Franklin KA, et al. 2001. Obstructive sleep apnoea syndrome is common in subjects with chronic bronchitis. Report from the Obstructive Lung Disease in Northern Sweden studies. Respiration, 68:250-5.

Leger P, Bedicam JM, Cornette A, et al. 1994. Nasal intermittent positive pressure ventilation. Long-term follow-up in patients with severe chronic respiratory insufficiency. Chest, 105:100-5.

Levi-Valensi P, Aubry P, Rida Z. 1990. Nocturnal hypoxemia and long-term oxygen therapy in COPD patients with daytime $\mathrm{PaO}_{2} 60-70 \mathrm{mmHg}$. Lung, 168(Suppl):770-5.

Levi-Valensi P, Weitzenblum E, Rida Z, et al. 1992. Sleep-related oxygen desaturation and daytime pulmonary haemodynamics in COPD patients. Eur Respir J, 5:301-7.

Lewis CA, Eaton TE, Fergusson W, et al. 2003. Home overnight pulse oximetry in patients with COPD: more than one recording may be needed. Chest, 123:1127-33.

Lightowler JV, Wedzicha JA, Elliott MW, et al. 2003. Non-invasive positive pressure ventilation to treat respiratory failure resulting from exacerbations of chronic obstructive pulmonary disease: Cochrane systematic review and meta-analysis. BMJ, 326:185.

Lin CC. 1996. Comparison between nocturnal nasal positive pressure ventilation combined with oxygen therapy and oxygen monotherapy in patients with severe COPD. Am J Respir Crit Care Med, 154:353-8.

McKeon JL, Murree-Allen K, Saunders NA. 1989. Supplemental oxygen and quality of sleep in patients with chronic obstructive lung disease. Thorax, 44:184-8.

McNicholas WT, Calverley PM, Lee A, et al; Tiotropium Sleep Study in COPD Investigators. 2004. Long-acting inhaled anticholinergic therapy improves sleeping oxygen saturation. Eur Respir J, 23:825-31.

McNicholas WT, Fitzgerald MX. 1984. Nocturnal deaths among patients with chronic bronchitis and emphysema. BMJ, 289:878.

Meecham Jones DJ, Paul EA, Jones PW, et al. 1995. Nasal pressure support ventilation plus oxygen compared with oxygen therapy alone in hypercapnic COPD. Am J Respir Crit Care Med, 152:538-44.

Midgren B, Hansson L. 1987. Changes in transcutaneous $\mathrm{PCO}_{2}$ with sleep in normal subjects and in patients with chronic respiratory diseases. Eur J Respir Dis, 71:388-94.

[MRC] Medical Research Council Working Party report. 1981. Long term domiciliary oxygen therapy in chronic hypoxic cor pulmonale complicating chronic bronchitis and emphysema. Lancet, i:681-6.

Mulloy E, McNicholas WT. 1993. Theophylline improves gas exchange during rest, exercise, and sleep in severe chronic obstructive pulmonary disease. Am Rev Respir Dis, 148:1030-6.

[NHLBI/WHO] National Heart, Lung, and Blood Institute and World Health Organization. 2005. Global initiative for chronic obstructive lung disease. Pocket Guide to COPD Diagnosis, Management, and Prevention. 2005 update [online]. Accessed on 14 March 2006. URL: http://www.goldcopd.com. 
[NOTT] Nocturnal Oxygen Therapy Trial group. 1980. Continuous or nocturnal oxygen therapy in hypoxemic chronic obstructive lung disease: a clinical trial. Ann Intern Med, 93: 391-398.

O’Donoghue FJ, Catcheside PG, Ellis EE, et al. 2003. Sleep hypoventilation in hypercapnic chronic obstructive pulmonary disease: prevalence and associated factors. Eur Respir J, 21: 977-84.

Pépin JL, Lévy P, Lepaulle B, et al. 1989. Evolution des désaturations nocturnes de 35 patients BPCO. Relation avec les données fonctionnelles et hémodynamiques. Rev Mal Respir, 6:357-64.

Perez-Padilla R, Conway W, Roth T, et al. 1987. Hypercapnia and sleep $\mathrm{O}_{2}$ desaturation in chronic obstructive pulmonary disease. Sleep, 10:216-23.

Perrin C, El Far Y, Vandenbos F, et al. 1997. Domiciliary nasal intermittent positive pressure ventilation in severe COPD: effects on lung function and quality of life. Eur Respir J, 10:2835-9.

Pilling J, Cutaia M. 1999. Ambulatory oximetry monitoring in patients with severe COPD: a preliminary study. Chest, 116:314-21.

Plywaczewski R, Sliwinski P, Nowinski A, et al. 2000 Incidence of nocturnal desaturation while breathing oxygen in COPD patients undergoing long-term oxygen therapy. Chest, 117:679-3.

Rasche, K, Duchna, HW, Orth, M, et al. 2001. Der Einfluss verschiedener Hypoxamiedefinitionen auf die Beziehung zwischen Pulmonalisdruck im Wachzustand und Hypoxamie im Schlaf bei COPD. Pneumologie, 55:289-94.

Sanders MH, Newman AB, Haggerty CL, et al. 2003. Sleep and sleepdisordered breathing in adults with predominantly mild obstructive airway disease. Am J Respir Crit Care Med, 167:7-14.

Servera E, Marin Pardo J, Fernandez E, et al. 1994. Long-term oxygen therapy. Is it necessary to increase the nocturnal flow by 1 liter? Chest, 106:1311.

Shepard JW Jr, Garrison MW, Grither DA, et al. 1985. Relationship of ventricular ectopy to nocturnal oxygen desaturation in patients with chronic obstructive pulmonary disease. Am J Med, 78:28-34.

Simonds AK, Elliott MW. 1995. Outcome of domiciliary nasal intermittent positive pressure ventilation in restrictive and obstructive disorders. Thorax, 50:604-9.
Sivasothy P, Smith IE, Shneerson JM. 1998. Mask intermittent positive pressure ventilation in chronic hypercapnic respiratory failure due to chronic obstructive pulmonary disease. Eur Respir J, 11:34-40.

Sliwinski P, Lagosz M, Gorecka D, et al. 1994. The adequacy of oxygenation in COPD patients undergoing long-term oxygen therapy assessed by pulse oximetry at home. Eur Respir J, 7:274-8.

Strumpf DA, Millman RP, Carlisle CC, et al. 1991. Nocturnal positivepressure ventilation via nasal mask in patients with severe chronic obstructive pulmonary disease. Am Rev Respir Dis, 144:1234-9.

Sullivan CE, Kozar LF, Murphy E, et al. 1979. Arousal, ventilatory, and airway responses to bronchopulmonary stimulation in sleeping dogs. J Appl Physiol, 47:17-25.

Tabachnik E, Muller NL, Bryan C, et al. 1981. Changes in ventilation and chest wall mechanics during sleep in normal adolescents. $J$ Appl Physiol, 51:557-64.

Tatsumi K, Kimura H, Kunitomo F, et al. 1986. Sleep arterial oxygen desaturation and chemical control of breathing during wakefulness in COPD. Chest, 90:68-73.

Tirlapur VG, Mir MA. 1982. Nocturnal hypoxemia and associated electrocardiographic changes in patients with chronic obstructive airways disease. $N$ Engl J Med, 306:125-30.

Vos PJ, Folgering HT, van Heerwarden CL. 1995. Predictors for nocturnal hypoxaemia (mean $\mathrm{SaO}_{2}<90 \%$ ) in normoxic and mildly hypoxic patients with COPD. Eur Respir J, 8:74-7.

White JE, Drinnan MJ, Smithson AJ, et al. 1995. Respiratory muscle activity during rapid eye movement (REM) sleep in patients with chronic obstructive pulmonary disease. Thorax, 50:376-82.

Wijkstra PJ, Guyatt GH, Ambrosino N, et al. 2001. International approaches to the prescription of long-term oxygen therapy. Eur Respir J, 18:909-13.

Zielinski J, MacNee W, Wedzicha J, et al. 1997. Causes of death in patients with COPD and chronic respiratory failure. Monaldi Arch Chest Dis, $52: 43-7$. 